A Doubter's Almanac

Ethan Canin

Random House, 2016

US\$28.00, 551 pages

ISBN: 978-1-4000-6826-5

Ethan Canin's novel A Doubter's Almanac follows fictional mathematician Milo Andret through several decades, including graduate school, winning a Fields Medal, and decline. The author is not a mathematician, although he was an engineering major at Stanford before switching his major to English. He then went on to obtain an MD degree before leaving medicine for a successful career in writing. Several of his novels, including the one under review, have made the New York Times bestseller list.

The first part of the book concentrates on Milo's life up to a few years after getting his PhD at UC Berkeley. A topologist, he receives his Fields Medal for proving the (fictional) Malosz conjecture. Now world-famous, he searches for another big open problem to tackle, finally deciding on the Abendroth conjecture (also fictional) after briefly considering the Goldbach conjecture (every even number greater than 2 is the sum of two primes). Milo's partial progress on the Abendroth conjecture leads to four excellent papers: one published in Annals of Mathematics, one in Acta Mathematica, and two in Inventiones. Milo's confidence that he will crack the Abendroth conjecture and reap even more fame is shattered when a proof of the Abendroth conjecture is discovered by a teenager.

Milo never recovers from losing the race to prove the Abendroth conjecture, and he is never again mathematically productive. The remaining 60 percent of the book deals with decades of decline and despair, focusing on

Sheldon Axler is professor of mathematics at San Francisco State University. His e-mail address is ax1er@sfsu. edu.

For permission to reprint this article, please contact:

reprint-permission@ams .org.

DOI: http://dx.doi.org/10.1090/noti1491
Milo's relationship with his family, especially his son, who is also a mathematician. At this point the book also has a dramatic shift of viewpoint, using a nice literary device that I will not disclose here because I enjoyed the surprise and do not want to spoil it for future readers.

Surely this novel's appearance on bestseller lists was not due to its mathematical context. I assume that nonmathematician readers were attracted by the beautifully written portrait of a seriously flawed genius and his family struggling with alcohol and drug problems in the midst of too many lies and deceptions. Although I appreciated the wellcrafted prose and loved the mathematical setting, I did not like the nasty Milo, and I found the last 60 percent of the book to be depressing.

All three universities at which fictional mathematician Milo Andret was a student or faculty member are also places where I was a student or faculty member (Princeton, UC Berkeley, Michigan State University). Thus I paid special attention to the representations of the mathematical culture of those institutions. Here are the most significant departures from reality that I noticed in this book:

- The book gives the following description of mathematics graduate students at UC Berkeley at the time that Milo was a graduate student there:

At the time, most of his classmates hoped to find jobs at Xerox in Palo Alto or at IBM in White Plains or at one of the industry-funded think tanks that were popping up now along the coast.

In fact, as I know because I was a graduate student at UC Berkeley at the same time as (the fictional) Milo, a large majority of our classmates wanted academic jobs. 


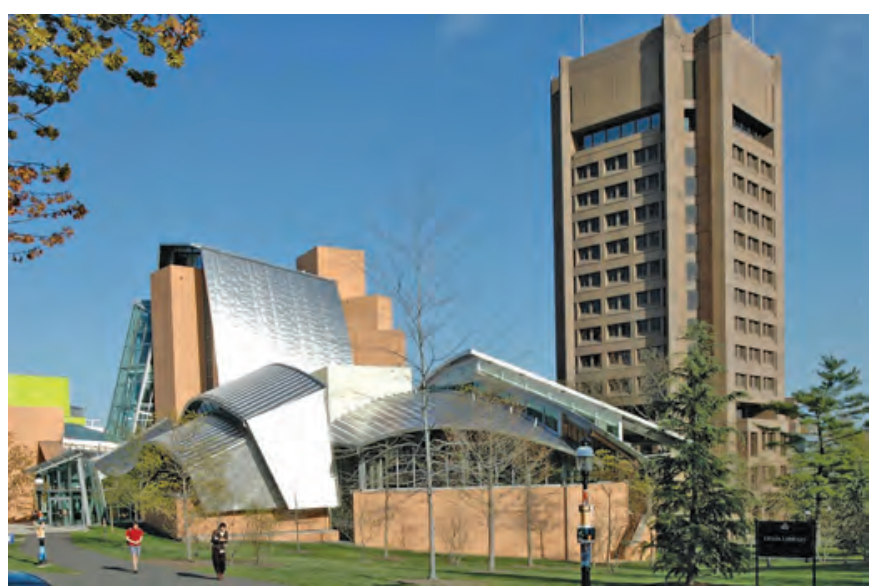

The main character in A Doubter's Almanac was a mathematics professor at Princeton University in the 1970s, with an office in Fine Hall, the tower on the right in this picture. Is the book accurate in suggesting that neckties were common attire among Princeton mathematicians in the 1970s? The reviewer, who earned his bachelor's degree at Princeton in 1971, remembers a largely necktie-free department.

- The book refers to the mathematics department at Princeton University as the

Department of Broken Englishes-that's how they were known around campus.

I was an undergraduate at Princeton a few years before the time of this remark, and I cannot recall ever hearing a complaint from a fellow student about the English language skills of any mathematics department faculty member.

- At one point when Milo is a tenure-track-but-stilluntenured faculty member in the Princeton mathematics department, he is called into a committee meeting of the nine most senior faculty members of the department. Here is the book's description of Milo's perception of this committee:

A startlingly uniform wall of bulbous Semitic features, threadbare sport coats, and colorless ties.

I am at a loss as to how to deal with the author's use of the phrase "bulbous Semitic features." Thus I will just mention the inaccuracy at the end of the sentence above: my memory as a student at Princeton is that faculty rarely wore ties, and I never saw anything like nine of them wearing ties.

- The Fields Medals are awarded at the once-every-fouryears meeting of the International Congress of Mathematicians (ICM). The Fields Medalists are notified in advance of their award so that they can be sure to attend the ICM, but otherwise the names of the winners are kept secret until the announcement at the ICM. That's how it goes in this novel. After Milo returns from the ICM, the chair of the Princeton mathematics department congratulates Milo on his award and on his discretion in not leaking it even to his colleagues, telling Milo:
That's a pretty big secret to keep.

Except it should not have gone that way because Milo was awarded the Fields Medal at the ICM held in Warsaw. That meeting of the ICM was originally scheduled for the summer of 1982 in Warsaw. However, in December 1981 martial law was declared in Poland and Solidarity was suppressed. The International Mathematical Union, which organizes the ICM, decided that the ICM could not be held in those conditions. Thus the ICM that was scheduled for 1982 was postponed until the summer of 1983, still in Warsaw. The International Mathematical Union announced the winners of the Fields Medal in 1982 rather than waiting until the postponed ICM in 1983. Thus the book is inaccurate in describing an element of secrecy concerning the announcement of Milo's Fields Medal at the Warsaw ICM.

- Late in the book, Milo's granddaughter is supposed to be reading Swiss Family Robinson, but her father discovers that she is actually reading

Zygmund and Fefferman's Trigonometric Se-

ries.

This is a family of geniuses, so I think it's a reasonable stretch to have a child reading this classic and highly respected work. However, the authorship above is wrong. The first edition of this book appeared in 1935, with Antoni Zygmund as the sole author. In 1959 an expanded second edition was published in two volumes, again with Zygmund as the sole author. In 2003 a third (and so far final) edition was published, with a forward by Robert Fefferman but still with Zygmund as the sole author. Mathematicians working in Fourier series refer to these volumes as "Zygmund." I have never heard anyone call them "Zygmund and Fefferman."

I noticed four more tiny errors, all less consequential than those discussed above. Overall, I consider the number of errors in this 551-page novel written by a nonmathematician about a mathematician to be remarkably low.

The author gets many big issues right. In particular, the novel does a fine job of depicting the difficult creative process of mathematics. The reader will come away with the understanding that even a superstar mathematician's research breakthroughs come only after being stuck with little progress for long periods of time.

Mathematicians who read this book will appreciate numerous tidbits that other readers will miss. For example, all the chapter titles have a mathematical meaning, starting with "Induction" as the title of the first chapter and ending with "Proof" as the title of the last chapter. As another example, Milo's daughter, Paulette, is named after Paul Erdős (the book gets the Hungarian double accute accent correct, in contrast to the incorrect umlaut that one often sees decorating this mathematician's name). Although the novel explains that Paul Erdôs is a famous mathematician, readers who are not mathematicians will probably be unaware of the startlingly unusual aspects of Erdős's career that Milo may have found attractive. 
Normally, book reviewers should not read other reviews of the book in question until after finalizing their own review. In this case, I broke that rule because the public perception of mathematics deserves our attention. Too often we see negative comments about mathematics in the media. One of my least favorite examples comes from the New York Times editorial in 1984 endorsing Walter Mondale for US president over Ronald Reagan. Trying to balance its positive comments about Mondale with something negative, the New York Times wrote:

Walter Mondale has all the dramatic flair of a trigonometry teacher.

To check whether the reviews of this book would be filled with such sentiments, I chose eight large cities in widespread geographic areas of the United States and looked for reviews of this book in the main newspaper of each of those cities. Seven of those eight newspapers (all except the Atlanta Journal-Constitution) reviewed this book in 2016, showing that this book received good exposure in popular culture. The reviews contained less hostility to mathematics than I had expected. The worst offender was the Washington Post, whose review said that the book

is a long, complex novel about math, which sounds like the square root of tedium, but suspend your flight instinct for a moment. Ethan
Canin writes with such luxuriant beauty and tender sympathy that even victims of Algebra II will follow his calculations of the heart with rapt comprehension.

The Boston Globe review of this book assumed that some of its readers have forgotten arithmetic that they learned in elementary school:

[O]ne need not have studied calculus (or even remember how to add and subtract fractions) to appreciate the book.

Two of the seven reviews that I read justifiably raised issues about the role of women in this book. Milo horribly mistreats his lovers, his wife, and his daughter, and they keep coming back for more. Canin's blinkered conception of his female characters strains credulity. After summarizing one incident in the book when a departmental secretary finally admits a drunken Milo into her hotel room, the reviewer for the New York Times wrote:

At this juncture of "no" meaning "yes" (not the only such in these pages), I took a moment to toss the book across the room.

Milo has one great mathematical triumph when he proves the Malosz conjecture, but everything else about his life reeks of disaster. I cannot imagine that any reader would want to be Milo, not even in return for a Fields Medal. The author's creation of Milo as a very unpleasant and extremely unhappy mathematical genius may be a literary success, but Milo is no role model.

\section{Photo Credit}

Photo of Princeton University is courtesy of Princeton University, Office of Communications; photo by Brian Wilson.

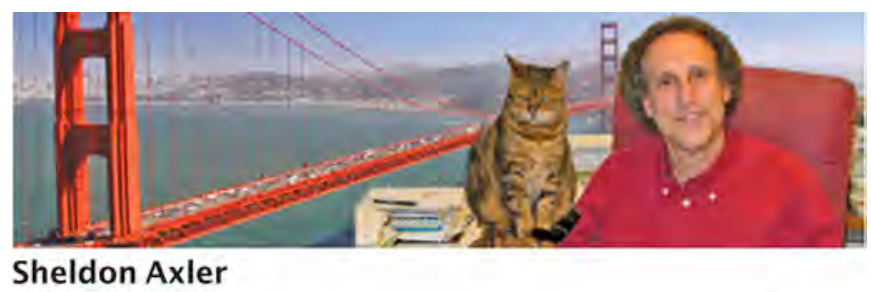

\section{ABOUT THE REVIEWER}

Sheldon Axler is the author of several books, including Linear Algebra Done Right, Harmonic Function Theory (with Paul Bourdon and Wade Ramey), and Precalculus: A Prelude to Calculus. He received the MAA's Lester R. Ford Award for expository writing in 1996. He was dean of the College of Science \& Engineering at San Francisco State University for thirteen years before returning full time to mathematics in 2015. He has served as a member of the Council of the AMS and as a member of the Board of Trustees of MSRI. 